\title{
Musings from the Research Infrastructure Task Force at Kansas State University
}

\section{Chris Sorensen}

Cortelyou-Rust University Distinguished Professor, Department of Physics, Kansas State University

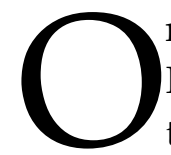

n January 19, 2010 President Schulz formed the Research Infrastructure Task Force (RITF) composed of 14 faculty, administration and staff. He asked me to chair the Task force, and I readily accepted. With a new president and an even newer provost, I saw the formation of this task Force as a bona fide opportunity to lay the foundation for much needed and positive change at the University. The president's charge to the Task Force was to take a broad and overarching approach to determine infrastructure needs for research at the University. We, the Task Force (TF), quickly interpreted this to mean that we should explore the entire basis of research, scholarship and creative activities (RSCA) that form the foundation of a modern, dynamic university.

To pursue our charge, I divided the TF into seven working groups of three to four people to study in depth key subject areas of infrastructure. These working groups were: Administration and Staffing, Equipment and Laboratories, Policies and Procedures, Equity across Disciplines, Graduate Students, Overhead Distribution, and External Interactions. The working groups would pursue their areas by finding data and developing recommendations. The entire TF met every other week to keep everyone informed and involved in the cumulative process. I "floated" among all the working group meetings. This process led us to create and use two surveys: the Faculty Survey which gathered data concerning faculty attitudes for RSCA; lab, office and building space; communal facilities; graduate students; etc., and a survey to all units requesting brief audits of their sponsored research overhead usage. All these efforts were then distilled to a large series of "findings" and "recommendations". An eighth working group of four, including me, was then tasked to write a report which was discussed at length several times by the entire TF as it evolved to completion. We took great pains to ensure that we said nothing that we could not back up with data and that our recommendations followed logically from the findings. The report was finished in mid June and submitted to the president. He made it public, and it can be found at:

http://www.kstate.edu/president/initiati ves/ritf/RITF final report.pdf

A major, and not at all surprising, finding is: Kansas State University is a 
student-centered, land-grant university where some fraction of the faculty pursues RSCA to various degrees in their fields of specialty. The public perception of K-State retains the studentcentered, land-grant descriptors and includes athletics. RSCA are largely ignored or not understood by the general public.

This rather innocuous finding is at the heart of the matter. Who is the faculty member who has not had a nonacademic acquaintance ask something like, "What are you going to do this summer, now that you don't have to teach"? In a similar vein it is likely that we faculty have all seen the surprise on our non-academic acquaintances when they discover that in the academic year we only teach three hours a week. We academics find these occurrences and their implied perceptions frustrating because we know that there is so much more to being a good academic than teaching.

Or do we? As frustrating as such perceptions are to a research active faculty member, they may be largely justified because the TF also found the following disturbing facts: At KSU

- A mere 10 units account for $\sim 56 \%$ of the University's external support.

- Some units have not even submitted applications for outside funding over much of the last decade.

- Many faculty do not consider RSCA as an integral and essential part of their duties.

Graduate students and the Graduate School are viewed as add-ons to the main activities of the University and not integral to its mission.

The TF found that there has been an attitude that at K-State we do RSCA too, not that we do RSCA, and a general malaise exists that RSCA is not as important as undergraduate education and athletics.

What to do about this dire situation? Here I propose a number of actions that could help greatly to remedy the situation. While my primary cause is the betterment of $\mathrm{KSU}$, the actions I propose could be useful at any university.

We start by defining a university:

A university is a place where a community of scholars can create new knowledge through research, scholarship and creative activities in an unfettered environment and disseminate that knowledge through teaching, scholarly activities, extension and outreach.

The University needs to clearly articulate this definition to the Board of Regents, the State legislature, the faculty (yes, remind the faculty!), the students, and the general population of the State.

With this, a new culture that advocates, expects and recognizes RSCA must be instilled from the top down, via the central administration, across all disciplines and units. This new culture must extend beyond the campus through the Foundation and the Alumni Association.

A list of action items is:

- We must make RSCA systemic.

- We must broaden our horizons for funding sources.

- We must elevate the stature of the Graduate School and graduate education and bring 
top-notch graduate students to our campus.

- We need centrally-supported, shared research facilities and new or renovated spaces thematically driven as opposed to departmentally structured.

- The Office of Research and Sponsored Programs must better meet faculty research needs.

- Central support is needed for organizing large research programs, archiving and coordinating campus resources (labs, equipment and people), and developing, with the collaboration of the Foundation and Alumni Association, prosperous relationships with a great variety of funding sources.

How do we accomplish these goals? Here again I humbly propose a number of actions that could help.

Use our resources. Perhaps the greatest resource of any university is the faculty. Across the faculty essentially any expertise can be found from quantum theory to starting a technical company, from plant genetics to crop advice, from poetry to publishing. We can solve our problems with our collective knowledge, "Physician, heal thyself"! Moreover, the faculty have a vested interest in improving the university, but they must be coordinated. Proper leadership, from the faculty, must be applied to coherently pursue goals related to the common good.

The faculty have to be properly supported and used. We must reward those who are productive and encourage and seed those who could be more active. For leadership the faculty could administer the RSCA enterprise as "rotators" into the administration properly compensated for a given duration of time in an area from which they would benefit.

We must encourage and augment collaboration. We must think and hire with an interdisciplinary, i.e., thematic, perspective. We must beware of territorial deans and department heads. We must build a university without walls!

The Foundation and the Alumni Association are major resources typically tapped for undergraduate affairs and athletics. It's time to use their great networks and interpersonal abilities to promote the "rest" of the university. It may well take some effort to get these bodies to buy in to the "new" definition of the university. The foundation should provide a concierge service to corporate entities. The Alumni Association should stress the importance of the research climate for teaching and the fact that post baccalaureate education is a major need in the modern world. Both must carry the banner of research, scholarship and creative activities to the masses and sell these as essential to both the university and to society as a whole.

Finally, let us not forget the synergy that exists in the best universities between teaching and the research, scholarship and creative activities enterprise. Yes, RSCA creates new knowledge for the good of our society. Yes, a viable RSCA enterprise at a university can give non-classroom experience to the students, and thus give them an important "non-academic" perspective. But in my opinion the 
greatest synergy comes from the fact that with a viable RSCA enterprise, our students can learn engineering from practicing engineers, poetry from real poets, business from experienced businessmen, and science from research scientists. The insights that these real practitioners have are invaluable and they cannot be found in the textbooks.

Acknowledgement. The Task Force members work very hard, conscientiously and collegially. They are:

- Betsy Cauble, Associate Professor of Social Work and Department Head, Sociology, Anthropology and Social Work; Faculty Senate President-Elect.

- Kara Dillard, Doctoral Candidate in Sociology, Graduate Student Council President.

- Shannon Fisher, Associate Controller, Controllers Office.

- James Guikema, Assoc. Vice President for Research and Professor, Div. of Biology.

- Mike Haddock, Assistant Dean, Research, Education and Engagement, K-State Libraries.

- Loretta Johnson, Associate Professor, Division of Biology.

- John Leslie, Professor and Head, Department of Plant Pathology.
- Daniel Marcus, University Distinguished Professor of Anatomy and Physiology.

- Denis Medeiros, Prof. and Head, Dept. of Human Nutrition/Assoc. Dean, Coll. of Human Ecol.

- Mary Rezac, Professor and CoDirector Sustainable Energy, Dept. of Chem. Engin.

- Carol Shanklin, Graduate School Dean and Professor, Hospitality Man. and Dietetics.

- Kerry Taylor, Asst. Vice President for Research (Animal Care); Director, Comp. Med.

- Karin Westman, Associate Professor and Department Head, Department of English.

- Administrative Assistants: Caron Berges, Senior Administrative Specialist to the Vice President for Research; Lisa Schubert, formerly Assistant to the Director of Governmental Relations.

- Task Force Chair: Chris Sorensen, Cortelyou-Rust University Distinguished Professor, Department of Physics.

See:

http://www.kstate.edu/president/initiati ves/ritf/RITF final report.pdf 